\title{
A Role for Bradyrhizobium japonicum ECF16 Sigma Factor EcfS in the Formation of a Functional Symbiosis with Soybean
}

\author{
S. B. Stockwell, ${ }^{1}$ L. Reutimann, ${ }^{2}$ and M. L. Guerinot ${ }^{1}$ \\ ${ }^{1}$ Biological Sciences Department, Dartmouth College, Hanover, NH 03755, U.S.A.; ${ }^{2}$ ETH, Institute of Microbiology, Zurich, \\ Switzerland
}

Submitted 12 July 2011. Accepted 18 August 2011.

\begin{abstract}
Alternative sigma $(\sigma)$ factors, proteins that recruit RNA polymerase core enzyme to target promoters, are one mechanism by which bacteria transcriptionally regulate groups of genes in response to environmental stimuli. A class of $\sigma^{70}$ proteins, termed extracytoplasmic function (ECF) $\sigma$ factors, are involved in cellular processes such as bacterial stress responses and virulence. Here, we describe an ECF16 $\sigma$ factor, EcfS (BIr4928) from the gram-negative soil bacterium Bradyrhizobium japonicum USDA110, that plays a critical role in the establishment of a functional symbiosis with soybean. Nonpolar insertional mutants of ecfS form immature nodules that do not fix nitrogen, a defect that can be successfully complemented by expression of ecfS. Overexpression of the cocistronic gene, tmrS (blr4929), phenocopies the ecfS mutant in planta and, therefore, we propose that TmrS is a negative regulator of EcfS, a determination consistent with the prediction that it encodes an anti- $\sigma$ factor. Microarray analysis of the ecfS mutant and $t m r S$ overexpressor was used to identify 40 transcripts misregulated in both strains. These transcripts primarily encode proteins of unknown and transport-related functions and may provide insights into the symbiotic defect in these strains.
\end{abstract}

The gram-negative soil bacterium Bradyrhizobium japonicum occupies two distinct niches: free-living in the soil and within specialized structures on soybean roots called nodules that form as part of an endosymbiotic relationship. B. japonicum must be able to sense and transition between these two environments, each with its own challenges: differing in the availability of nutrients, $\mathrm{pH}$, and oxygen concentration. One generalized way in which bacteria respond to changing environmental conditions is by altering their transcriptional profile through the use of alternative $\sigma$ factors. These proteins fall into two structurally distinct families $\left(\sigma^{54}\right.$ and $\left.\sigma^{70}\right)$, each with the ability to interact with and recruit RNA polymerase core enzyme to consensus sequences within the promoters of target genes (Brooks and Buchanan 2008; Gruber and Gross 2003).

This study is focused on the characterization of 1 of 15 putative $B$. japonicum strain USDA110 group IV $\sigma^{70}$ proteins, also

Current address for S. B Stockwell: Department of Integrated Science and Technology, James Madison University, Harrisonburg, VA, 22807 U.S.A.

Corresponding author: S. B. Stockwell; E-mail: stockwsb@jmu.edu

* The $e$-Xtra logo stands for "electronic extra" and indicates that three supplementary tables are published online. known as extracytoplasmic function $(\mathrm{ECF}) \sigma$ factors (Kaneko et al. 2002b; Staron et al. 2009). Bacterial ECF $\sigma$ factors, comprising 43 distinct groups, represent the most diverse and abundant class of $\sigma^{70}$ proteins (Staron et al. 2009). Although first appreciated for their role in cell envelope stress responses, the diversity of function and complexity of the protein networks controlled by these proteins has been expanding as the number of characterized ECF $\sigma$ factors has grown. What unifies ECF $\sigma$ factors is the presence of only two (regions 2 and 4) of the four conserved functional domains found in groups 1,2, and 3 of the $\sigma^{70}$ protein family (Gruber and Gross 2003; Kazmierczak et al. 2005). Genes encoding ECF $\sigma$ factors are often clustered with those encoding cognate negative regulators, collectively termed anti- $\sigma$ factors (Staron et al. 2009). The majority of ECF anti- $\sigma$ factor proteins span the cytoplasmic membrane, allowing for outside-in signal transduction by way of periplasmic sensory and cytoplasmic response domains (Staron et al. 2009). However, a collection of ECF $\sigma$ factors (subgroups ECF11-15) are regulated by anti- $\sigma$ factors located in the cytoplasm (Bastiat et al. 2010; Gourion et al. 2009; Staron et al. 2009). ECF15 (also called EcfG-like) $\sigma$ factors are additionally indirectly regulated by anti-anti- $\sigma$ factor-like membrane-spanning response regulator proteins of the PhyR family (Bastiat et al. 2010; Gourion et al. 2009; Staron et al. 2009). The sole characterized B. japonicum ECF $\sigma$ factor, EcfG, belongs to this subgroup (Gourion et al. 2009).

EcfG-like (group ECF15) $\sigma$ factors have been shown to function in the general stress response of $\alpha$-proteobacteria (Staron et al. 2009). EcfG-like RpoE2 plays this role in Sinorhizobium meliloti, in which it is required for a variety of stress responses (i.e., stationary phase survival in the presence of high levels of hydrogen peroxide, desiccation, and growth in hyperosmotic conditions), presumably due to the transcriptional control of a large regulon of stress-associated genes (Flechard et al. 2009, 2010; Humann et al. 2009; Sauviac et al. 2007; Staron et al. 2009). Likewise, mutants of B. japonicum ecfG demonstrate an increased sensitivity to desiccation and thermal stress following carbon starvation (Gourion et al. 2009). Unlike $S$. meliloti rpoE2, which is dispensable for symbiosis, B. japonicum ecfG is involved in forming an efficient symbiosis with mungbean and soybean (Gourion et al. 2009). Plants inoculated with ecfG mutants are slow to develop nodules and those that do form are often aberrantly shaped and produce ectopically emerging roots (Gourion et al. 2009). Soybean plants nodulated by the ecfG mutant recover a functional symbiosis by 4 weeks postinoculation, suggesting a role for EcfG in early but not necessarily late stages of the symbiosis (Gourion et al. 2009). 
With a well-documented role for ECF $\sigma$ factors in virulence and the recent link between ECF $\sigma$ factor EcfG and the $B . j a$ ponicum-soybean symbiosis, we hypothesized that there may be other ECF $\sigma$ factors present in B. japonicum that are dedicated to adaptation to the symbiotic niche. Furthermore, we predicted that such a symbiosis-specific ECF $\sigma$ factor would not be required for general stress responses but, rather, may respond to a signal unique to the in planta environment. Here, we describe the initial characterization of the extracytoplasmic function $\sigma$ factor for symbiosis (ecfS) (blr4928) and its cocistronic gene transmembrane regulator of symbiosis (tmrS)

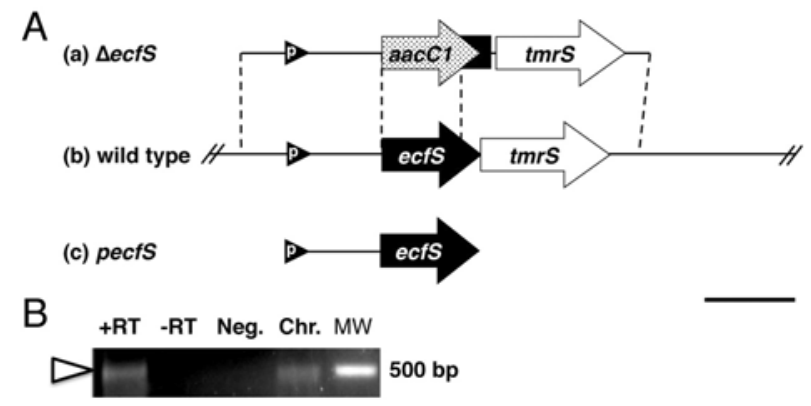

Fig. 1. ecfS and tmrS cocistronic genomic organization, mutant and plasmid construction, and end-point reverse-transcriptase polymerase chain reaction (RT-PCR) analysis. A, (a) Extracytoplasmic function (ECF) $\sigma$ factor deletion/insertion (i.e., $\Delta e c f:$ :aacC1) mutant construction compared with the (b) wild-type chromosomal allele as well as the (c) complementation plasmid. A and B, Scale bar represents approximately $500 \mathrm{bp}$ of DNA. The region containing the presumptive ecfS promoter (based on predicted -10/35 sites at approximately 370 and 391 bp upstream of the ecfS translational start site; BPROM online promoter prediction tool) is indicated by small black arrowheads labeled with "p". The ecfS promoter was predicted to be located within 500 bp upstream of the ecfS start codon. The black box at the end of $a a c C 1$ in construct (a) represents the $40 \mathrm{bp}$ from the end of ecfS that remains in this construct to allow for a ribosome binding site for $t m r S$. B, End-point RT-PCR was used to amplify a 500-bp region spanning the ecfS-tmrS open reading frames from wild-type USDA110derived cDNA. Products are shown (white arrowhead). Lanes from left to right: $+\mathrm{RT}=\mathrm{PCR}$ product resulting from wild-type cDNA made with $\mathrm{RT}=-\mathrm{RT}$ and Neg., minus RT and no template control reactions yielding no products; Chr., positive chromosomal DNA control reaction; MW, molecular weight ladder with relevant band size indicated. (blr4929) by way of mutational and transcriptomic analysis. In other bacteria, ECF $\sigma$ factors have been shown to control nearby genes (e.g., FecI regulation of downstream fecABCDE in Escherichia coli) (Braun et al. 2006); thus, blr4928 and blr4929 were of particular interest due to their close genomic proximity (i.e., within eight open reading frames [ORF]; approximately $7.5 \mathrm{kbp}$ ) to the USDA110 ferrichrome receptor gene (i.e., bll4920) (Small et al. 2009) whose homolog in strain 61A152 (i.e. $f e g A$ ) has been implicated in the symbiosis (Benson et al. 2005). Results show that other than a slight growth defect characterized by an extended lag phase, cultured cells of ecfS mutants have no discernible in vitro phenotypes under the conditions tested. However, either loss of ecfS or overexpression of $t m r S$ blocks early stages of the symbiosis, suggesting that the proper balance of EcfS and TmrS is critical for in planta bacterial adaptation.

\section{RESULTS}

ecfS and $t m r S$ are contained within one transcriptional unit.

The ecfS and $t m r S$ coding regions are on the same strand and overlap by 4 bp within the $B$. japonicum USDA110 genome (Kaneko et al. 2002b); thus, we hypothesized that these genes make up one transcriptional unit. Using end-point reverse-transcriptase polymerase chain reaction (RT-PCR), we amplified a 500-bp DNA fragment spanning the ecfS-tmrS ORF junction (Fig. 1B. +RT lane) from wild-type USDA110-derived cDNA. No product was observed in either the -RT or no-template control reactions, although a robust 500-bp band was observed in the positive control reaction containing purified USDA110 chromosomal DNA (Fig. 1B; -RT, Neg., and Chr. lanes).

\section{$\Delta e c f S$ mutants have a severe symbiotic defect.}

$\mathrm{ECF} \sigma$ factors are known to be required for the virulence of a variety of bacterial pathogens (Kazmierczak et al. 2005; Llamas et al. 2009; Rowley et al. 2006). Because B. japonicum is able to persist in association with its plant host, in a manner similar to that of intracellular bacterial pathogens, we tested an ecfS deletion mutant for its ability to form a functional symbiosis with soybean. A dramatic phenotype is observed when

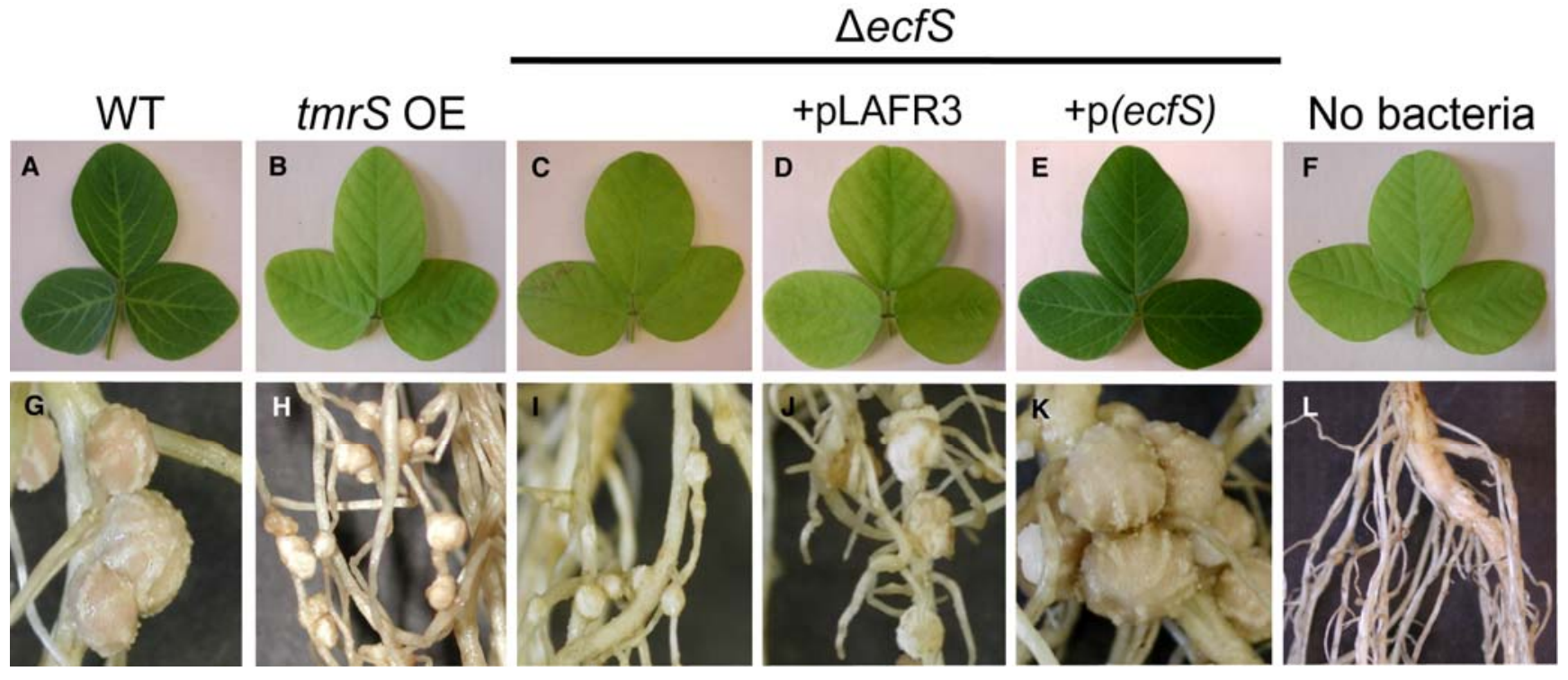

Fig. 2. Nonfunctional symbiosis, characterized by the formation of small nodules resulting in chlorotic plants, occurs upon deletion of ecfS or overexpression of $t m r S$. A to F, Leaf and $\mathbf{G}$ to $\mathbf{L}$, root nodule photographs of 5-week-old soybean plants inoculated with A and G, USDA110; B and $\mathbf{H}$, tmrS overexpressor $(\mathrm{OE}) ; \mathbf{C}$ and $\mathbf{I}, \Delta e c f S ; \mathbf{D}$ and $\mathbf{J}, \Delta e c f S / p L A F R 3 ; \mathbf{E}$ and $\mathbf{K}, \Delta e c f S / p e c f S ;$ or $\mathbf{F}$ and $\mathbf{L}$, no bacteria are shown. The entire root crown of a representative mock inoculated plant is shown. The ecfS mutant defect can be complemented by expression of ecfS in trans. 
soybean plants are inoculated with $\Delta$ ecfS. These plants form many $(34 \pm 5 \Delta e c f S$ versus $5 \pm 1$ wild-type nodules per gram fresh shoot weight), small nodules $(1.0 \pm 0.2 \mathrm{mg}$ of $\Delta e c f S$ versus $19.2 \pm 1.0 \mathrm{mg}$ of wild-type nodules) (Figs. 2 and 3). $\Delta e c f S$ mutant nodules do not contain leghemoglobin, consistent with an inability to fix nitrogen. Plants inoculated with $\Delta e c f S$ are extremely chlorotic, presumably because these plants are starved for nitrogen (Figs. 2C and I and 3B). Nitrogenase activity of the inoculated roots was not measured due to the obvious nature of the nitrogen starvation. $\Delta e c f S$ symbiotic phenotypes are fully complemented by the introduction of a wildtype copy of ecfS in trans, expressed from $500 \mathrm{bp}$ of upstream sequence (Figs. 2E and $\mathrm{K}$ and 3 ). The mutant carrying the empty vector is indistinguishable from the $\Delta e c f S$ strain in plant assays (Figs. 2D and $\mathrm{J}$ and 3 ). When plants were grown in nutrientrich soil with sufficient levels of nitrogen, the presence or absence of bacteria (i.e., wild-type USDA110 or $\Delta e c f S$ ) had no impact on soybean germination or growth.

To further characterize the $\Delta e c f S$ symbiosis defect, nodules formed on plants inoculated with $\Delta e c f S, \Delta e c f S / p L A F R 3$, or $\Delta e c f S /$ pecfS were harvested at 5 weeks postinoculation and viewed by transmission electron microscopy (TEM). Although nodules infected with the complemented strain contain many symbiosome-filled cells (indistinguishable from nodules infected with wild-type USDA110), there were no bacteria observed in nodules from plants inoculated with either the $\Delta e c f S$ or the $\Delta e c f S / p L A F R 3$ strain (Fig. 4). Plant cells from nodules induced by $\Delta e c f S$ or $\Delta e c f S / p L A F R 3$ appeared empty, with little or no cytoplasmic material, unlike what is typically observed for uninfected cells (Fig. 4D and E, cells labeled "UN"). Additionally, nodule cell shape (Fig. 4A to C) and cell wall thickness is irregular (Fig. 4A). Unlike cells inoculated with bacteria capable of eliciting a normal symbiosis, recognizable mitochondria and nuclei are rarely observed in ecfS mutant-induced nodules (Fig. 4A to C). Only one discernable nucleus (Fig. 4C) was observed in all of the mutant nodule sections. Additionally, because no bacteria or infection threads were observed in these nodules, we believe that the mutant bacteria are defective in nodule invasion. This is supported by our inability to recover mutant cells from inoculated plants.

Overexpression of $\mathrm{tmrS}$ results in a severe symbiotic defect, indistinguishable from that of $\Delta e c f S$.

tmrS (blr4929) is predicted to encode a typical ECF16-associated protein with a conserved domain (DUF1109; six transmembrane spanning regions placing both the $\mathrm{N}$ and $\mathrm{C}$ termini in the cytoplasm) of unknown function (Staron et al. 2009). To assess TmrS's possible role as an anti- $\sigma$ factor protein and, thus, a negative regulator of the symbiosis, an overexpressor (OE) strain was created in lieu of a deletion. In doing so, an additional copy of the $t m r S$ ORF was introduced into the chromosome of wild-type strain USDA110, resulting in a merodiploid strain. The $t m r S$ gene was cloned downstream of and, therefore, expressed from the predicted endogenous ecfS promoter. As expected, the introduction of an additional copy of $t m r S$ in the merodiploid strain resulted in a 3.8-fold overexpression of tmrS over wild-type USDA110 levels (as shown by microarray analysis; data not shown) and, thus, the strain was termed the tmrS OE.

Indistinguishable from $\Delta e c f S$, the $t m r S$ OE has a severe symbiotic defect compared with USDA110 (Figs. 2B and $\mathrm{H}$ and 3). Plants inoculated with the tmrS OE produce large numbers $(27 \pm 3$ nodules/g of fresh shoot) of tiny nodules $(0.6 \pm$ $0.1 \mathrm{mg} /$ nodule) at levels similar to those formed on plants infected with $\Delta e c f S$ ( $34 \pm 5$ nodules/g of fresh shoot; $1.0 \pm 0.2$ $\mathrm{mg} /$ nodule) (Figs. 2 and 3 ).

\section{Stress sensitivity of $\Delta e c f S$ is similar to the wild type.}

Due to the well-established role of some ECF $\sigma$ factors in environmental stress response and survival, $\Delta e c f S$ was tested
A

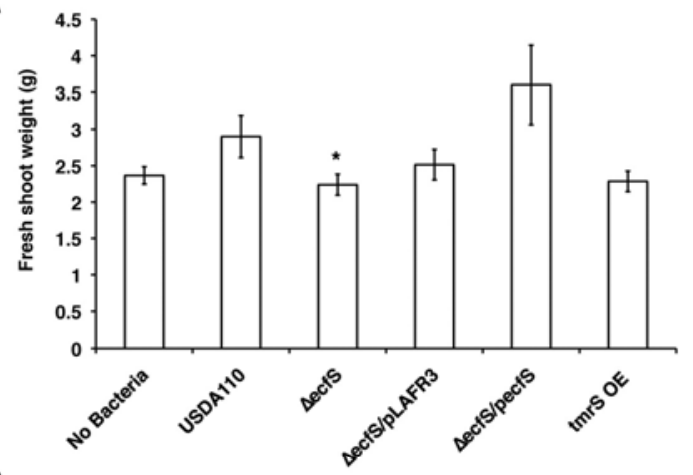

C

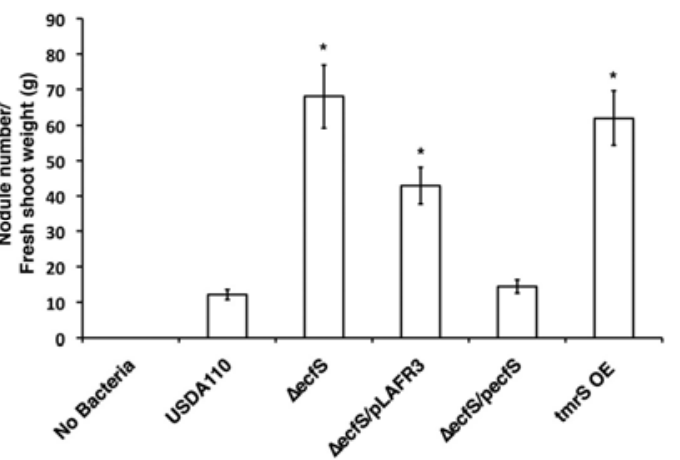

B

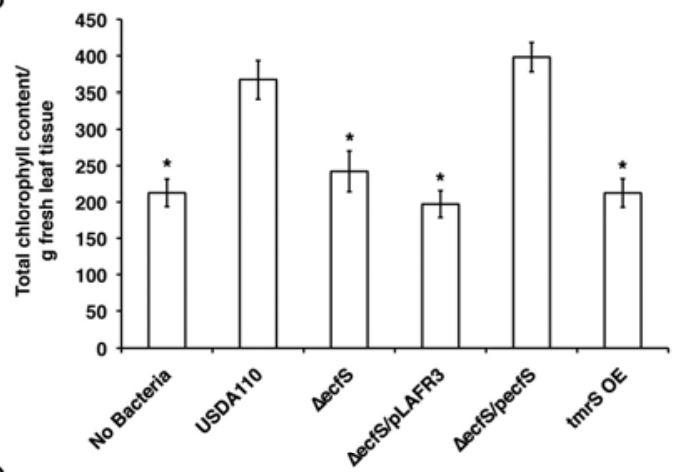

$\mathrm{D}$

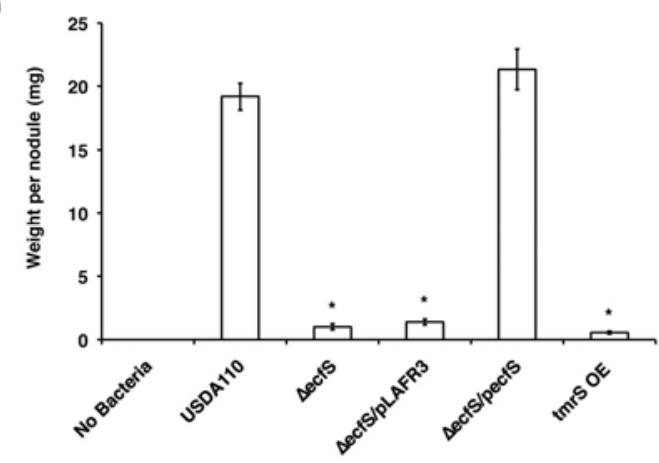

Fig. 3. Quantification of the symbiosis formed by various strains infecting soybean plants. Seeds were inoculated and plants were grown and harvested at 5 weeks postinoculation with planting. A, Shoots were separated from roots and weighed. B, Chlorophyll was extracted from plant leaves and quantified. C, Nodules were removed from roots, counted, and normalized per gram fresh shoot weight. D, Picked nodules were weighed. Standard error of the mean is shown ( $n=7$ to 39). Asterisks indicate Student's $t$ test $P$ values of $<0.04$ (A) or $<0.001$ (B to D) compared with wild-type levels. 
for increased sensitivity to oxidative stress, detergents, and extreme $\mathrm{pH}$, as assessed by measuring growth inhibition zones on plates containing point-deposited hydrogen peroxide, sodium dodecyl sulfate (SDS), $\mathrm{NaOH}$, or $\mathrm{HCl}$. The growth inhibition zone diameters of the wild type and the ecfS mutant strain are similar upon the addition of hydrogen peroxide (wild type, $34.1 \pm 0.6 \mathrm{~mm} ; \Delta e c f S, 36.2 \pm 0.9 \mathrm{~mm}$ ), SDS (approximately $22 \mathrm{~mm}$ in diameter), $\mathrm{NaOH}$ (approximately $19 \mathrm{~mm}$ ), or $\mathrm{HCl}$ (approximately $10.5 \mathrm{~mm}$ ) (Fig. 5). Similar results were observed when experiments were performed on cells grown to late log phase and resuspended and incubated for $20 \mathrm{~h}$ in minimal media $\pm 0.2 \%$ xylose (data not shown).

\section{Transcriptome analysis reveals similarly} misregulated genes in the ecfS mutant and tmrS OE.

Microarray analysis was used to identify $\Delta e c f S /$ pLAFR 3 and $t m r S$ OE misregulated transcripts in hopes of elucidating a cause for the common symbiotic defect of these strains. The complemented mutant ( $\Delta$ ecfS/pecfS) and wild-type USDA110 strains were used as functional symbiont controls. The transcriptome experiment was performed on cultured cells to circumvent technical difficulties associated with the in planta environment. That is, the inability to recover ecfS mutant cells from inoculated plants makes it impossible to isolate enough in-planta-derived bacterial mRNA for microarray analysis. Genes with at least a twofold change in expression above or below wild-type levels when grown in peptone salts-yeast extract (PSY) broth under standard laboratory conditions were included in the analysis. Using this criterion, 791, 487, and 743 misregulated transcripts were identified in $\Delta e c f S / p L A F R 3$, tmrS OE, and $\Delta$ ecfS/pecfS cultures, respectively, compared with the wild type (Fig. 6A). It was found that there was a 2.6fold increase in tmrS expression over wild-type levels in the ecfS mutant, confirming that the in-frame aacCl ORF insertion in this strain is not polar on downstream gene $t m r S$ (data not shown). A 3.8-fold overexpression of $t m r S$ was confirmed in the merodiploid $t m r S$ OE compared with the wild type (data not shown). ecfS expression was below threshold detection levels in all strains (data not shown), most likely due to inherently low levels of expression from the endogenous promoter. Phenotypic changes in the complemented mutant suggest that ecfS levels in this strain, although undetectable, are sufficient for the symbiosis.

Because transcripts similarly misregulated in $\Delta$ ecfS/pecfS and the ecfS mutant or tmrS OE strain are most likely not responsible for the symbiosis phenotypic differences observed, these genes were removed from further analyses. Thus, 419 (i.e., 222 and 197) and 316 (i.e., 222 and 94) were extracted from the ecfS mutant and tmrS OE lists, respectively (Fig. 6A). Of the remaining transcripts, there were found to be 332 (179 below and 153 above wild-type levels; Supplementary Table S2) and 131 (57 below and 74 above wild-type levels; Supplementary Table S3) transcripts uniquely misregulated in the

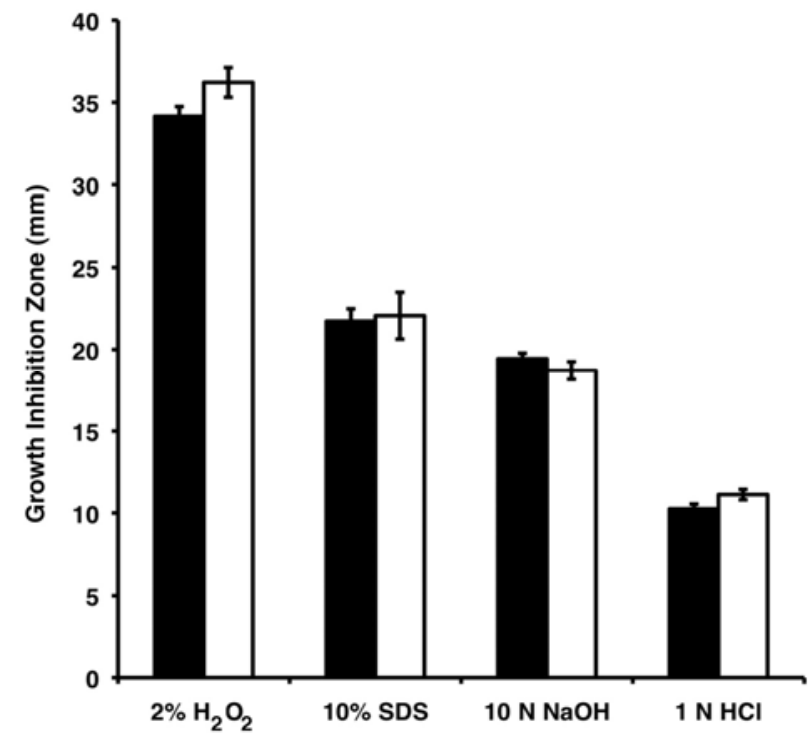

Fig. 5. The ecfS mutant is not hypersensitive to oxidative (hydrogen peroxide)-, detergent (sodium dodecyl sulfate [SDS])-, or extreme $\mathrm{pH}(\mathrm{NaOH}$ or $\mathrm{HCl}$ )-induced cell stress compared with the wild type. Plate sensitivity assays were performed on USDA110 (black bars) and $\Delta$ ecfS (white bars). Bacterial lawns were plated and various solutions were point deposited into the center of each plate. The diameter of growth inhibition zones around each compound was quantified. Standard error of the mean is shown ( $n$ values of 14 to 21 ).

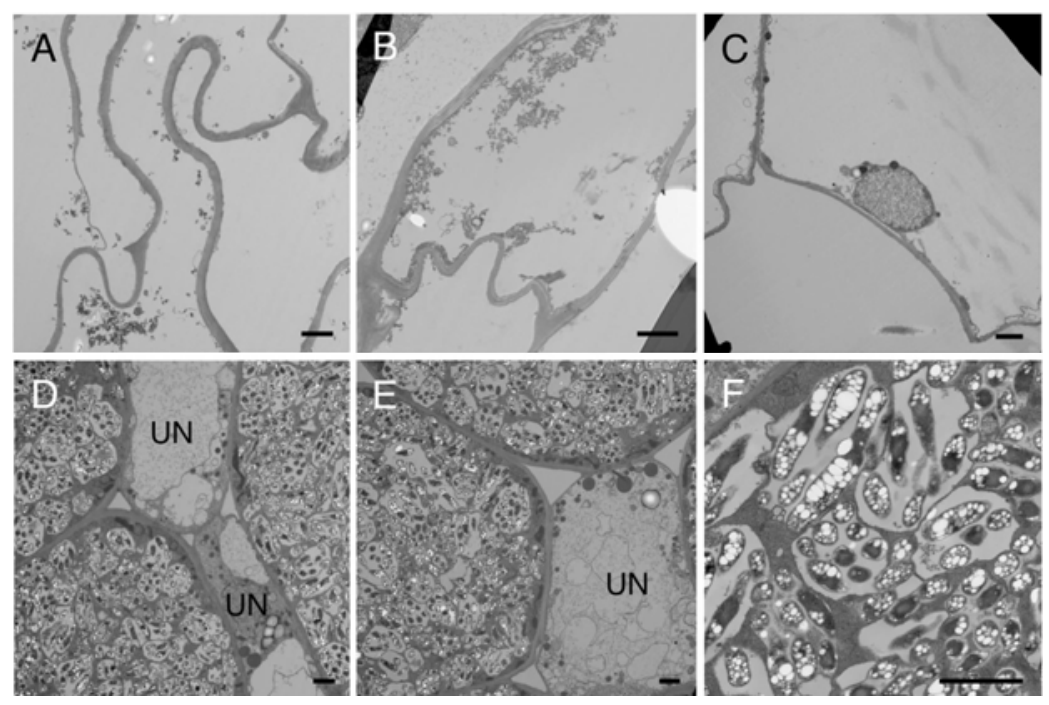

Fig. 4. Representative transmission electron micrographs of nodules formed on plants inoculated with the ecfS mutant and complemented strains. Nodules were harvested from 5-week-old soybean plants inoculated with $\mathbf{A}$ and $\mathbf{B}, \Delta e c f S$ or $\mathbf{C}, \Delta e c f S / p L A F R 3$ or $\mathbf{D}, \mathbf{E}$, and $\mathbf{F}, \Delta e c f S / p e c f S$. Scale bars represent $2 \mu \mathrm{m}$. $\Delta e c f S$ mutant-infected nodule cells are irregularly shaped and have altered cell wall thickness and few identifiable organelles. No infection threads or bacterial cells were observed in $\Delta e c f S$ - or $\Delta e c f S /$ pLAFR3-infected nodules. $\Delta e c f S / p e c f S$-infected nodules contain many symbiosomes, visible organelles, and few uninfected cells (UN). These nodules are indistinguishable from those infected with wild-type Bradyrhizobium japonicum) (wild-type images not shown) (Benson et al. 2005; Libault et al. 2011). 
ecfS mutant or tmrS OE strain, respectively (Fig. 6A). In all, 40 transcripts (13 below and 27 above wild-type levels) were misregulated in both the ecfS mutant and tmrS OE strain and, thus, represent a subset of particularly promising genes for determining the cause of the symbiotic defect of these strains (Fig. 6). Of note, only one of these transcripts (bll3387, hypothetical protein) was differentially regulated in the ecfS mutant (i.e., down, 0.312) and $t m r S$ OE (i.e., up, 2.388) strains. A complete list of the $40 \Delta e c f S / p L A F R 3$ and $t m r S$ OE overlapping misregulated transcripts is provided in Table 1.

The general functional groups represented in the ecfS mutant, $t m r S \mathrm{OE}$, and overlapping gene lists were derived from the genome annotation put forth by Kaneko and associates (2002a and b) and are summarized in Figure 6B. In all lists, there was a bias toward transcripts predicted to encode proteins of hypothetical or unknown functions $(38.5 \%$, ecfS mutant; $57.3 \%$, tmrS OE; $40 \%$, overlap; $30.1 \%$, full genome) (Kaneko et al. 2002a). In the ecfS mutant and $\Delta e c f S-t m r S$ OE overlap lists, there was also a bias toward transcripts predicted to encode proteins with transport-related functions (19.9\%, ecfS mutant; $20 \%$, overlap; $9 \%$, full genome) (Kaneko et al. 2002a).

\section{DISCUSSION}

B. japonicum USDA110 is predicted to contain $15 \mathrm{ECF} \sigma$ factors with representatives of nine subgroups (i.e., ECF15, 16, 18, 20, 26, 29, 33, 41, 42) (Staron et al. 2009) (Table 2). Although there is a generalized understanding of subgroups ECF01 to -10 due to previously characterized founding members, little is known about subgroups 11 to 43 (Staron et al. 2009). Thus, the characterization of the B. japonicum ECF $\sigma$ factors, all of which are members of relatively novel subgroups, is sure to lead to a more thorough understanding of the role and mechanism of ECF $\sigma$ factors in bacterial adaptation and survival.

Because the transition between the free-living state and symbiosis with host legumes involves a series of adaptive steps, we hypothesized that one or more B. japonicum ECF $\sigma$ factor is involved in altering gene expression for this adaptation. Here, as an extension of this hypothesis, we describe the identification and initial characterization of ECF16 subgroup $\sigma$ factor, EcfS (Blr4928). We have confirmed that ecfS is in an operon with an overlapping downstream gene, $\operatorname{tmrS}$ (Fig. 1), and have demonstrated a specific and dramatic in planta phenotype of the nonpolar (confirmed by microarray analysis) ecfS mutant we constructed. No $\Delta$ ecfS stress-related in vitro phenotypes have been identified under the culture conditions tested; thus, we conclude that EcfS is not likely to be required for general stress responses. This is in agreement with the classification of EcfS as an Ecf16 (i.e., not an Ecf15- or EcfG-like, general stress-response-associated) $\sigma$ factor protein (Staron et al. 2009). Rather, due to the severe symbiotic defect of the ecfS mutant, we believe that EcfS functions primarily in the bacterial adaptation to the in planta environment.

Because $t m r S$ overexpression (3.79-fold over wild-type levels) phenocopies the ecfS mutant in planta, we propose that TmrS functions as a negative regulator in the symbiosis. Thus, EcfS and TmrS perform opposing functions in planta, and perhaps it is the appropriate functional balance between these proteins that allows the bacteria to establish themselves in the symbiosis. This is supported by the results of our transcriptomic analysis. Specifically, loss of EcfS in the ecfS mutant leads to a 2.6-fold increase in $t m r S$ expression compared with the wild type (data not shown). This may be due to compensatory enhanced transcriptional activity at the shared ecfStmrS promoter in response to the loss of EcfS function in the ecfS mutant. Although it has been proposed that $t m r S$ encodes a typical ECF16-associated anti- $\sigma$ factor containing a DUF1109 domain and six transmembrane regions (Staron et al. 2009), future studies are needed to examine possible TmrS-EcfS protein interactions typical of $\sigma$ factor-anti- $\sigma$ factor partners.

Based on the immature nodules and lack of observable infection threads that formed on plants inoculated with $\Delta e c f S$, we conclude that active EcfS is required for the early stages of nodule formation and plant invasion. However, the initial stages of infection (i.e., root hair deformation in response to Nod factor production) are unaffected by this mutation, as assessed by the formation of immature nodules. None of the genes misregulated in the ecfS mutant encode proteins necessary for Nod factor production or have been shown to be induced by the soybean isoflavonoid, genistein (Lang et al. 2008). In support of a role for EcfS and TmrS in the early infection process, only 2 of the 40 misregulated genes identified in both the ecfS mutant and tmrS OE via microarray have altered expression in differentiated bacteroids compared with free-living cells (Table 1) (Chang et al. 2007; Pessi et al. 2007). Future characterization of the EcfS or TmrS regulon may involve the quantification of nod or genome-wide gene expression in planta.

Interestingly, over time, the nodules formed by plants inoculated with $\Delta e c f S( \pm$ pLAFR3) and tmrS OE undergo one of two fates: nodule senescence or the transition back into roots via the formation of a growing root tip (data not shown). Based on
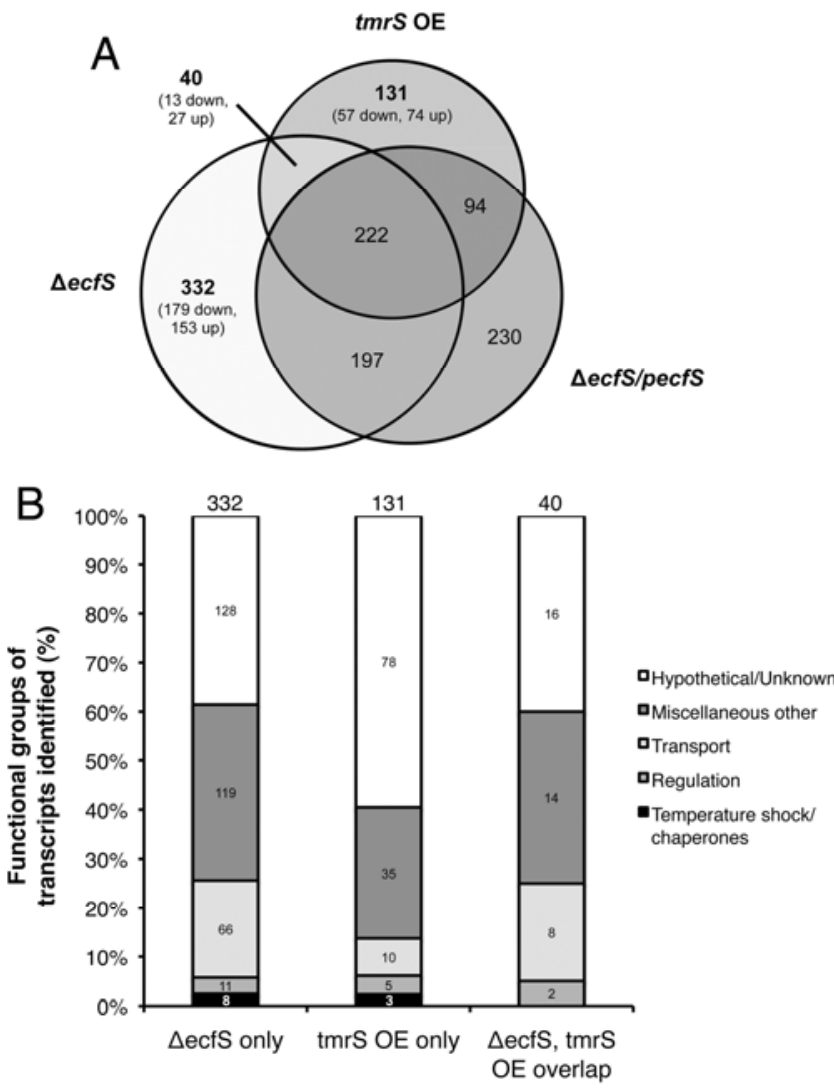

Fig. 6. Summary of transcripts found to be misregulated a minimum of twofold change above or below wild-type levels in $\Delta e c f S / p L A F R 3, t m r S$ overexpressor (OE), and $\Delta$ ecfS/pecfS. A, Proportional Venn diagram of misregulated transcripts in each strain compared with wild-type USDA110. The number of total transcripts represented by each fraction of the diagram is indicated. The breakdown of up- and downregulated genes in each category is shown, where relevant. B, Summary of functional groups represented in the $332 \Delta e c f S / p L A F R 3$ only, $131 \mathrm{tmrS}$ OE only, and $40 \Delta e c f S$ tmrS OE overlapping misregulated transcripts. Functional groups have been derived from the genome annotation put forth by Kaneko and associates (2002). 
this observation, we propose that the nodules formed by these plants have not fully differentiated into nodule organs and, upon the apparent halt in infection, they are able to transition back into roots. The protrusion of root tips from immature nodules was similarly reported of nodules induced by ecfG mutants (Gourion et al. 2009). However, the ecfS mutant phenotype is more severe than that of ecfG because, unlike for ecfG-inoculated soybean, plants infected with $\Delta e c f S$ do not establish a symbiosis over time (Gourion et al. 2009). We propose that EcfS and EcfG perform different roles in the cell. In support of this, none of the misregulated transcripts identified in the ecfS mutant or tmrS OE strain have been shown to be
EcfG regulated and no EcfG-binding motifs (GGAAC-N15GCGT) were identified in the upstream regions of these genes (Gourion et al. 2009).

Based on the precedence of in vitro stress hypersensitivity of ECF $\sigma$ mutants, we hypothesized that the symbiotic defect of the ecfS mutant may be due to a general lack of fitness of this strain. In vitro analysis of the ecfS mutant reveals a modest hypersensitivity to oxidative stress, yet sensitivity to extreme $\mathrm{pH}$, detergents, or hypersalinity; extended stationary phase survival; and exopolysaccharide production are unaltered in this strain (Fig. 5) (data not shown). Transcriptome analysis yielded few misregulated chaperone-encoding genes in the ecfS mutant

Table 1. List of the 40 Bradyrhizobium japonicum transcripts misregulated $\geq$ twofold above or below wild type USDA110 levels in both $\Delta$ ecfS/pLAFR 3 and tmrS overexpressor (OE) when grown under standard laboratory conditions

\begin{tabular}{|c|c|c|c|c|}
\hline \multirow[b]{2}{*}{ Genome $^{\text {b }}$} & \multirow[b]{2}{*}{ ORF description ${ }^{c}$} & \multicolumn{2}{|c|}{$n$ Fold-change $(P \text { value })^{a}$} & \multirow[b]{2}{*}{ Functional category $^{d}$} \\
\hline & & $\Delta e c f S / p L A F R 3$ & tmrS OE & \\
\hline bll3387 & Unknown protein & $0.312(0.00118)$ & $2.388(0.00385)$ & Hypothetical/unknown \\
\hline bsl4527 & Unknown protein & $0.462(0.00403)$ & $0.456(0.0055)$ & Hypothetical/unknown \\
\hline bsl5453 & Hypothetical protein & $0.303(6.01 \mathrm{e}-5)$ & $0.484(0.00373)$ & Hypothetical/unknown \\
\hline$\underline{b l l 7424}$ & Hypothetical protein & $0.41(0.000295)$ & $0.46(0.000645)$ & Hypothetical/unknown \\
\hline$\overline{\text { blr6798 }}$ & Transcriptional regulatory protein IclR family & $0.491(0.00279)$ & $0.458(0.000518)$ & Regulation \\
\hline blr1064 & $\mathrm{ABC}$ transporter permease protein & $0.304(0.00307)$ & $0.268(0.00215)$ & Transport \\
\hline blr1065 & $\mathrm{ABC}$ transporter permease protein & $0.272(0.0072)$ & $\mathbf{0 . 2 5 8}(0.00365)$ & Transport \\
\hline blr1066 & $\mathrm{ABC}$ transporter ATP-binding protein & $0.436(0.00117)$ & $0.408(0.00194)$ & Transport \\
\hline blr2437 & $\mathrm{ABC}$ transporter ATP-binding protein & $\mathbf{0 . 2 1 5}(0.001)$ & $0.473(0.00313)$ & Transport \\
\hline bll3149 & Putative oxalate:formate antiporter & $0.33(0.0097)$ & $0.317(0.00893)$ & Transport \\
\hline$\underline{b l r 1818^{*}}$ & RhcQ; component of type III secretion system & $0.431(0.00128)$ & $0.441(0.000954)$ & $\begin{array}{l}\text { Other; protein and peptide } \\
\text { secretion/trafficking }\end{array}$ \\
\hline$\underline{b l r 1819}^{* \wedge}$ & RhcR; component of type III secretion system & $0.415(0.000364)$ & $0.384(7.82 \mathrm{e}-5)$ & $\begin{array}{l}\text { Other; protein and peptide } \\
\text { secretion/trafficking }\end{array}$ \\
\hline bll6039 & Probable SgaA serine-glyoxylate aminotransferase & $0.438(0.00326)$ & $0.464(0.00534)$ & Other; amino acid biosynthesis \\
\hline bsl0728 & Hypothetical protein & $2.77(0.000456)$ & $2.065(0.000461)$ & Hypothetical/unknown \\
\hline bll0800 & Hypothetical protein & $3.14(0.00039)$ & $2.337(0.000875)$ & Hypothetical/unknown \\
\hline bllo888 & Hypothetical protein & $6.18(7.38 \mathrm{e}-5)$ & $3.496(7.54 \mathrm{e}-5)$ & Hypothetical/Unknown \\
\hline$\underline{b s r 1784^{\wedge}}$ & Unknown protein & $2.35(0.00335)$ & $2.127(0.00493)$ & Hypothetical/unknown \\
\hline$\underline{\text { bll2158 }}$ & Unknown protein & $3.62(0.00235)$ & $2.458(0.00456)$ & Hypothetical/unknown \\
\hline$\overline{b l r 2564}$ & Hypothetical protein & $3.98(0.00028)$ & $2.109(0.00115)$ & Hypothetical/unknown \\
\hline blr4131 & Unknown protein & $2.20(4.43 e-5)$ & $2.045(7.4 \mathrm{e}-5)$ & Hypothetical/unknown \\
\hline$\overline{\text { bll5155 }}$ & Hypothetical protein & $3.11(4.31 \mathrm{e}-5)$ & $2.267(0.000225)$ & Hypothetical/unknown \\
\hline$\underline{b l r 5730}$ & Hypothetical protein & $2.02(0.00182)$ & $2.036(0.00216)$ & Hypothetical/unknown \\
\hline$\overline{b l r 5841}$ & Hypothetical protein & $2.09(0.00323)$ & $2.315(0.00124)$ & Hypothetical/unknown \\
\hline$\overline{b l r 7300}$ & Unknown protein & $3.94(0.0079)$ & $4.257(0.00656)$ & Hypothetical/unknown \\
\hline bll7395 & Hypothetical protein & $2.54(4.05 e-5)$ & $2.254(6.12 \mathrm{e}-5)$ & Hypothetical/unknown \\
\hline bll0620 & Two-component response regulator & $3.12(0.000138)$ & $2.135(2.21 \mathrm{e}-5)$ & Regulation \\
\hline$\underline{b l r 0462}$ & Probable $\mathrm{ABC}$ transporter permease protein & $2.31(0.00314)$ & $2.154(0.00231)$ & Transport \\
\hline blr1516 $\mathrm{Fe}$ & AcrB, RND multidrug efflux transporter & $3.02(0.000119)$ & $3.037(0.000234)$ & Transport \\
\hline blr2314 & MFS permease & $2.10(0.00157)$ & $3.213(0.000191)$ & Transport \\
\hline blr0149 & Cytochrome $\mathrm{O}$ ubiquinol oxidase subunit II & $2.02(0.00176)$ & $2.357(0.00127)$ & Other; energy metabolism \\
\hline blr0151 & Cytochrome O ubiquinol oxidase subunit III & $2.99(0.00277)$ & $2.826(0.00311)$ & Other; energy metabolism \\
\hline blr0152 & Cytochrome $\mathrm{O}$ ubiquinol oxidase subunit IV & $2.68(0.00015)$ & $2.49(0.0011)$ & Other; energy metabolism \\
\hline$\underline{b l l 0246}$ & Indoleacetamide hydrolase (EC 3.5.1.-) & $2.02(0.00305)$ & $3.214(0.000437)$ & $\begin{array}{l}\text { Other; biosynthesis of cofactors, prosthetic } \\
\text { groups and carriers }\end{array}$ \\
\hline blr1201 $\mathrm{Fe}$ & 3-Dehydroquinate dehydratase & $2.40(0.00268)$ & $2.35(0.00169)$ & Other; amino acid biosynthesis \\
\hline blr1253 & Dehydrogenase & $3.27(4.62 \mathrm{e}-5)$ & $2.044(9.57 \mathrm{e}-5)$ & Other; central intermediary metabolism \\
\hline bll1418 & Methionine synthase & $2.01(0.00243)$ & $3.089(0.000128)$ & Other; amino acid biosynthesis \\
\hline$\underline{b l l 1419}$ & 5,10-Methylenetetrahydrofolate reductase & $2.58(0.00249)$ & $3.578(0.000371)$ & Other; amino acid biosynthesis \\
\hline$\overline{b l r 2511}$ & Molybdopterin biosynthesis protein B & $2.53(0.000445)$ & $2.156(0.000778)$ & $\begin{array}{l}\text { Other; biosynthesis of cofactors, prosthetic } \\
\text { groups and carriers }\end{array}$ \\
\hline bll $5700^{\mathrm{Fe} \#}$ & Hypothetical glutathione S-transferase-like protein & $2.83(3.0 \mathrm{e}-5)$ & $2.653(0.000271)$ & Other; detoxification \\
\hline bll $7966^{\mathrm{Fe}}$ & Putative thiosulfate sulfurtransferase & $2.42(0.000506)$ & $2.27(0.000483)$ & Other \\
\hline
\end{tabular}

${ }^{a}$ Expression values are reported as $n$-fold change above or below wild-type USDA110 levels. Genes with a $\geq$ twofold change in expression compared with the wild type are listed in numerical order within general functional categories. Corresponding $P$ values are shown in parentheses.

${ }^{\mathrm{b}}$ Genome open reading frame (ORF) number. Genes misregulated in the ecfS mutant were cross referenced with those reported to be regulated by EcfG, RegR, NifA, RpoN ${ }_{1 / 2}$, Irr, genistein, symbiosis (i.e., in bacteroids), desiccation, oxygen, or iron availability. There was no overlap in the EcfG and EcfS regulons (Gourion et al. 2009). The 11 RegR-regulated transcripts are underlined (Hauser et al. 2006; Lindemann et al. 2007). The one Irr-regulated transcript is indicated by the presence of a pound sign superscript (\#) (Yang et al. 2006). The four transcripts previously found to be regulated in bacteroids or microaerophilic conditions are indicated by the presence of an asterisk $(*)$ or caret $\left({ }^{\wedge}\right)$ sign, respectively (Chang et al. 2007; Hauser et al. 2006; Pessi et al. 2007). The four transcripts regulated in B. japonicum strain LO under iron limitation are indicated by the presence of an Fe superscript (Yang et al. 2006). None of the transcripts were shown to have altered expression in response to desiccation (Cytryn et al. 2007), genistein (Lang et al. 2008), or the loss of Nif A or RpoN $1 / 2$ (Hauser et al. 2006, 2007). The fold-change values of the most up- and downregulated genes compared with the wild type are indicated in bold.

${ }^{c}$ ORF nomenclature and descriptions are based on those established by Kaneko and associates (2002).

${ }^{\mathrm{d}}$ General functional categories are those put forth by Kaneko and associates (2002). 
and $t m r S$ OE strain, none of which were common to both strains (Table 1). These results suggest that the loss of a functional symbiosis in the ecfS mutant and $t m r S$ OE is not due to compromised general stress responses or cell envelope integrity.

We were unable to ascertain any substantial conserved nucleotide motifs, including the ECF16-like promoter recognition site (TGTAAC(C/A)N16CGAA) (Staron et al. 2009), within the putative promoters of ecfS/pLAFR3 or tmrS OE misregulated genes; therefore, we propose that they do not compose one uniform regulon but, rather, a collection of direct and indirect targets. Thus, the EcfS regulon could not be determined through these studies. However, extrapolation of our transcriptome data implicates a general defect in the regulation of transport-related functions in the mechanism of the ecfS mutant and $t m r S$ OE symbiotic defects. Future characterization of the misregulated genes, particularly those encoding hypothetical or unknown functions, will undoubtedly lead to a more thorough mechanistic understanding.

As a culmination of the data presented here, we propose a model in which EcfS functions in an early stage of nodulation.
Based on its predicted sequence and structural similarity to ECF $\sigma$ factors, we propose a model in which EcfS promotes the symbiosis by binding to and recruiting RNAP core enzyme to the promoters of target genes as an indirect response to an environmental or plant-specific cue encountered during the early infection process. TmrS negatively affects symbiosis, a role consistent with that of an anti- $\sigma$ factor. Loss of EcfS or hyperactivity of TmrS leads to the same end: the inability of the bacteria to establish themselves in the symbiotic niche. Thus, we propose that the balance of EcfS or TmrS levels within a hypothesized regulatory network is critical for a proper bacterial response. Future work will focus on the elucidation of potential protein-protein interactions of EcfS with TmrS, and RNA Pol core enzyme.

\section{MATERIALS AND METHODS}

Bacterial strains, plasmids, enzymes, and chemicals.

All strains and plasmids used in this study are listed in Table 3. Escherichia coli strains were routinely grown in Luria-Ber-

Table 2. Predicted Bradyrhizobium japonicum USDA110 extracytoplasmic function (ECF) $\sigma$ and anti- $\sigma$ factor genes

\begin{tabular}{|c|c|c|c|c|c|}
\hline $\begin{array}{l}\text { Genome } \\
\text { number }\end{array}$ & $\begin{array}{l}\text { Gene } \\
\text { name }\end{array}$ & $\begin{array}{c}\text { ECF } \\
\text { subgroup }^{a}\end{array}$ & $\begin{array}{l}\text { Associated anti- } \sigma \\
\text { factor gene }\end{array}$ & $\begin{array}{l}\text { Known or putative } \\
\text { cocistronic genes }^{b}\end{array}$ & References or other notable features \\
\hline blr7797 & $e c f G$ & 15 & nepR (blr7796) & nepRecfG & Gourion et al. 2009 \\
\hline blr3038 & $\ldots$ & 16 & blr3039 & blr3038-3039 & $\ldots$ \\
\hline blr4928 & ecfS & 16 & tmrS (blr4929) & ecfStmrS & $\begin{array}{l}\text { Downstream of the USDA110 ferrichrome receptor } \\
\text { (bll4920) (Small et al. 2009) }\end{array}$ \\
\hline blr2203 & $\ldots$ & 18 & $\ldots$ & bll2201-2203 & Clustered with flagellar synthesis genes $(f l i I,-J)$ \\
\hline blr3694 & $\ldots$ & 20 & $\ldots$ & blr3694-3701 & Clustered with flagellar synthesis genes (flaA, flgE, flaN) \\
\hline bll6484 & ecfA & 26 & bll6483 & bll6488-6483 & $\ldots$ \\
\hline bll2628 & prtI & 26 & bll2627 & bll2628-2627 & $\ldots$ \\
\hline bll3014 & $\ldots$ & 26 & bll3013 & bll3016-3011 & $\ldots$ \\
\hline blr 2557 & $\ldots$ & 29 & $\ldots$ & blr2555-2559 & $\ldots$ \\
\hline blr3042 & $\ldots$ & 33 & $\ldots$ & blr3042-3043 & $\ldots$ \\
\hline bll1028 & $\ldots$ & 33 & $\ldots$ & bll1032-1023 & $\ldots$ \\
\hline blr 7812 & $\ldots$ & 41 & $\ldots$ & blr7812-7816 & $\ldots$ \\
\hline bll6612 & $\ldots$ & 42 & $\ldots$ & $\ldots$ & $\ldots$ \\
\hline bll0085 & $\ldots$ & 42 & $\ldots$ & bll0091-0085 & $\ldots$ \\
\hline bll7170 & $\ldots$ & 42 & $\ldots$ & bll7170-7168 & $\ldots$ \\
\hline
\end{tabular}

${ }^{a}$ ECF subgroups determined by Staron and associates (2009).

${ }^{\mathrm{b}}$ Based on Kaneko and associates (2002b).

Table 3. Bacterial strains and plasmids used in this study

\begin{tabular}{|c|c|c|}
\hline Strain or plasmid & Relevant characteristics & Source or reference \\
\hline \multicolumn{3}{|l|}{ Strains } \\
\hline \multicolumn{3}{|l|}{ Bradyrhizobium japonicum } \\
\hline USDA110 & Nitrogen-fixing Glycine max symbiont & Guerinot and Chelm 1986 \\
\hline$\Delta e c f S:: a a c C 1$ & USDA110 ecfS ORF deletion/replacement strain $\left(\mathrm{Gm}^{\mathrm{r}}\right)$ & This work \\
\hline $\operatorname{tmrS}$ overexpressor $(\mathrm{OE})$ & 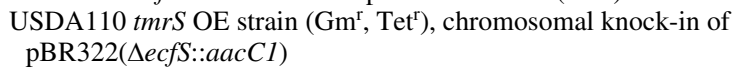 & This work \\
\hline $61 \mathrm{~A} 152$ & $\ldots$ & EMB Crop Bioscience, Brookfield, WI, U.S.A. \\
\hline \multicolumn{3}{|l|}{ Escherichia coli } \\
\hline DH5 $\alpha$ & $\begin{array}{l}\text { hsdR17 endA1 thi-1 gyrA96 relA1, recA1 supE44 } \Delta l a c U 169 \\
\text { ( } 880 \text { dlacZDM15) }\end{array}$ & Gibco-BRL, Gaithersburg, MD, U.S.A. \\
\hline \multicolumn{3}{|c|}{ 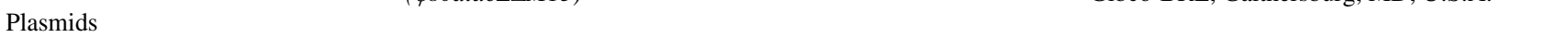 } \\
\hline pBR322 & $\begin{array}{l}\text { Tet }^{\mathrm{r}}, \mathrm{Amp}^{\mathrm{r}} \text { Escherichia coli cloning vector, B. japonicum suicide } \\
\text { vector }\end{array}$ & Bolivar et al. 1977; Watson 1988 \\
\hline pRK2013 & Kan helper plasmid for mobilization & Figurski and Helinski 1979 \\
\hline pGEM-T Easy & $A m p^{r}$ cloning vector & Promega, Madison, WI, U.S.A. \\
\hline pLAFR3 & Tet $^{\mathrm{t}}$ broad host range plasmid for $B$. japonicum expression & Staskawicz et al. 1987 \\
\hline pBBR1-MCS5 & $\mathrm{Gm}^{\mathrm{r}}$ broad host range plasmid & Kovach et al. 1995 \\
\hline $\mathrm{pAC} \Omega \mathrm{GM}$ & Plasmid carrying the $\mathrm{Gm}^{\mathrm{r}}$ cassette $(a c c C I)$ & Schweizer 1993 \\
\hline pGEM-TE (ecfS) & $\begin{array}{l}\text { pGEM-T Easy carrying USDA110 ecfS with 500-bp upstream } \\
\text { sequence }\end{array}$ & This work \\
\hline pGEM-TE ( $\Delta e c f S:: a a c C 1-t m r S)$ & pGEM-T Easy carrying $750 \mathrm{bp}$ upstream of ecfS fused to aac $C 1$ & $\mathrm{~T}$ \\
\hline pLAFR3 (ecfS) & $\begin{array}{l}\text { Insert of pGEM-TE (ecfS) subcloned into pLAFR3 at the EcoRI } \\
\text { site of the MCS }\end{array}$ & This work \\
\hline
\end{tabular}

${ }^{\mathrm{a}} \mathrm{ORF}=$ open reading frame; $\mathrm{OE}=$ overexpressor; and $\mathrm{Gm}^{\mathrm{r}}$, $\mathrm{Tet}^{\mathrm{r}}$, and $\mathrm{Amp}^{\mathrm{r}}$ indicate resistance to gentamycin, tetracycline, and ampicillin, respectively. 
tani media at $37^{\circ} \mathrm{C}$ with shaking. B. japonicum USDA110 cultures were grown in arabinose-gluconate (AG), yeast extract media supplemented with xylose, or PSY media with shaking, or on plates at $30^{\circ} \mathrm{C}$. When necessary, antibiotics were supplemented as follows: for $E$. coli, ampicillin $(100 \mu \mathrm{g} / \mathrm{ml})$, tetracycline $(20 \mu \mathrm{g} / \mathrm{ml})$, and gentamycin $(15 \mu \mathrm{g} / \mathrm{ml})$; and for B. japonicum, tetracycline $(200 \mu \mathrm{g} / \mathrm{ml})$, gentamycin $(200-250 \mu \mathrm{g} / \mathrm{ml})$, and rifampicin $(40 \mu \mathrm{g} / \mathrm{ml})$. T4 DNA ligase and all restriction enzymes were purchased from New England Biolabs (Beverly, MA, U.S.A.). The pGEM-T Easy vector system was purchased from Promega Corporation (Madison, WI, U.S.A.). Polymerases were purchased from Stratagene (La Jolla, CA, U.S.A.) (PFU-Ultra High Fidelity Polymerase), Takara (Otsu, Japan) (ExTaq), and Roche (Nutley, NJ, U.S.A.) (Amplitaq) while primers were synthesized and purchased from Integrated DNA Technologies (Coralville, IA, U.S.A.).

\section{Molecular techniques and mutagenesis.}

Mutant and plasmid constructs are listed in Table 3 and illustrated in Figure 1. Full primer sequences are listed in Supplementary Table S1.

\section{End-point RT-PCR of ecfStmrS.}

Wild-type USDA110 cells were grown in AG broth to an optical density at $600 \mathrm{~nm}$ of 0.6 . Cells were harvested by centrifugation and total RNA was extracted using a Quick-RNA MiniPrep kit (following the manufacturer's instructions; Zymo Research, Irvine, CA, U.S.A.) with the addition of a 30-min on-column DNase treatment (RNase-free DNase set; Qiagen, Valencia, CA, U.S.A.). Approximately $1 \mu \mathrm{g}$ of total RNA was converted to cDNA using a high-capacity cDNA RT kit equipped with MultiScribe RT, 10× RT buffer, $4 \mathrm{mM}$ dNTPs, and random primers (Applied Biosystems, Carlsbad, CA, U.S.A.). A negative control reaction, in which RT was omitted, was run in parallel. The RT reaction conditions were as follows: $25^{\circ} \mathrm{C}$ for $10 \mathrm{~min}, 37^{\circ} \mathrm{C}$ for $120 \mathrm{~min}, 85^{\circ} \mathrm{C}$ for $5 \mathrm{~min}$, and $10^{\circ} \mathrm{C}$ for $30 \mathrm{~min}$. A fraction of each cDNA reaction (i.e., \pm RT) served as a template in end-point PCR with AmpliTaq DNA Polymerase (Applied Biosystems) and primers (P1 and P2) designed to flank the ecfS-tmrS ORF junction. Additional control reactions contained no template or $100 \mathrm{ng}$ of purified USDA110 chromosomal DNA. One-fifth of each reaction was separated through a $1 \%$ agarose gel and visualized via ethidium bromide staining.

\section{Creation of a B. japonicum USDA110 ecfS nonpolar deletion mutant and a tmrS OE strain.}

Overlap extension PCR was used to replace the ecfS ORF with the gentamycin resistance gene $(a a c C l)$ to create a synthetic operon of $a a c C l$ and $t m r S$ driven by the endogenous ecfS promoter (Fig. 1A). Three DNA fragments were amplified corresponding to 750 bp of ecfS upstream sequence (primers $\mathrm{P} 3 / \mathrm{P} 5$; presumably containing the ecfS promoter and terminating at the ecfS GTG start codon), the ORF conferring gentamycin resistance (primers $\mathrm{P} 6 / \mathrm{P} 7$; aacC1), and 750 bp of ecfS downstream sequence (primers P8/P4; including the last $39 \mathrm{bp}$ of the ecfS ORF and the entire $t m r S$ ORF). Using homologous sequences engineered into each fragment, the three pieces were spliced together using overlap extension PCR (primers $\mathrm{P} 3 / \mathrm{P} 4)$, creating $\Delta$ ecfS::aacC1-tmrS. This product was purified and cloned into pGEM-T Easy using TA overhangs added by ExTaq polymerase, creating pGEM-TE( $\Delta$ ecfS::aacC1-tmrS). The insert was verified by PCR and sequencing. Next, $\Delta$ ecfS::aacCl-tmrS was subcloned using flanking BamHI sites engineered into the construct, and cloned into a similarly cut B. japonicum suicide plasmid, pBR322. pBR322(_ecfS::aacC1tmrS) was conjugated into $B$. japonicum USDA110 via tripar- ental mating. B. japonicum clones containing the pBR322 ( $\Delta$ ecfS::aacCl-tmrS) plasmid recombined onto the chromosome were selected with tetracycline $(200 \mu \mathrm{g} / \mathrm{ml})$, and $E$. coli donor and helper strains were counterselected using rifampicin $(40 \mu \mathrm{g} / \mathrm{ml})$. These clones were verified as single-crossover meridiploid strains by confirmation of the mutant allele by screening for gentamycin resistance and PCR. As shown by subsequent microarray analysis, these meridiploid strains overexpress $t m r S$ 3.27-fold over wild-type USDA110 (data not shown), because they contain an additional copy of the $t m r S$ ORF (driven by $750 \mathrm{bp}$ of its endogenous promoter) knocked into the ecfStmrS locus. One of the meridiploid strains, containing the pBR322 backbone on the chromosome, was passaged six times in antibiotic-free AG broth, diluted, and plated for single colonies. These colonies were screened for tetracycline and gentamycin resistance, indicative of a second crossover event leading to loss of the wild-type ecfS allele. Gentamycin-resistant, tetracycline-sensitive clones were confirmed as $\Delta$ ecfS::aacC1 mutants by colony PCR and Southern blot (data not shown). Herein, this mutant strain is denoted " $\Delta$ ecfS". The putative ecfS promoter sequence, spacing, and $t m r S$ upstream sequence (presumably containing the $t m r S$ ribosome binding site) is maintained in the ecfS mutant. Microarray analysis reveals a 2.6-fold increase in tmrS expression in $\Delta e c f S$ compared with the wild type, confirming the presumption that $t m r S$ expression is not impaired in this strain.

\section{Complementation of $\Delta e c f S$.}

The $\Delta e c f S$ mutant complementation plasmid was made as follows: ecfS (including 500 bp of upstream sequence) was amplified, using primers $\mathrm{P} 9 / \mathrm{P} 10$, from the $B$. japonicum USDA110 genome using the high-fidelity polymerase, PFU Ultra (Stratagene) (Fig. 1A). The product was initially cloned into the pGEM-T Easy vector system by TA-overhangs added to the PCR product by ExTaq polymerase following amplification, creating pGEMTE(ecfS). The insert was released from the pGEM-T Easy backbone with EcoRI and subcloned into a similarly cut low-copy plasmid, pLAFR3, for expression in $B$. japonicum. This created complementation plasmid pLAFR3(ecfS). Both pLAFR3(ecfS) and the empty pLAFR3 vector were conjugated into $\Delta e c f S$ by triparental mating and selected with tetracycline at $200 \mu \mathrm{g} / \mathrm{ml}$. E. coli was counterselected using rifampicin at $40 \mu \mathrm{g} / \mathrm{ml}$. Resulting B. japonicum clones were confirmed to contain the appropriate pLAFR3 complementation plasmids by PCR.

\section{In vitro analysis of the mutant hypersensitivity to environmental stresses.}

Some ECF $\sigma$ factors are known to regulate genes required for survival in the face of environmental stress; therefore, the $\sigma$ mutants were tested for hypersensitivity to oxidative stress, detergents, and extreme $\mathrm{pH}$. Late-exponential to early-stationary phase AG liquid cultures of B. japonicum USDA110 and $\Delta$ ecfS were diluted and plated onto AG plates to create a lawn of bacteria. To test for sensitivity to oxidative stress, detergents, and $\mathrm{pH}, 3 \mu \mathrm{l}$ of $2 \% \mathrm{H}_{2} \mathrm{O}_{2}, 7 \mu \mathrm{l}$ of $10 \%$ SDS, $5 \mu \mathrm{l}$ of $10 \mathrm{~N} \mathrm{NaOH}$, or $10 \mu \mathrm{l}$ of $1 \mathrm{~N} \mathrm{HCl}$ were added to the toothpick holes or sterile filter disks (in the case of SDS) in the center of each plate. Following 5 to 10 days of incubation at $30^{\circ} \mathrm{C}$, the growth inhibition zones surrounding the added solutions were quantified. In addition to plate assays, a long-term stationary-phase survival assay was performed on the wild-type and mutant strains. In this assay, cultures were grown to stationary phase and viable cell counts were determined at $4,7,14,21$, and 28 days postinoculation. Because no difference was observed between the strains, this data has been excluded from this report. There was also no difference in Calcofluor white or Congo Red bind- 
ing, or hypersensitivity to salt of the ecfS mutant compared with wild-type and complemented strains (not shown).

\section{Symbiosis assays.}

Glycine max soybean seed (Yellow butterbean; Johnny's Selected Seed, Ambion, ME, U.S.A.) were sterilized and inoculated with washed B. japonicum cultures or mock inoculated with sterile water, as previously described by Benson and associates (2005). Plants were grown for 5 weeks in modified, sterilized Leonard jars containing nitrogen-free medium (Benson et al. 2005). Shoots were separated from roots and weighed. Nodules were counted and weighed. For TEM, 1- $\mathrm{mm}^{3}$ cubes were cut from the centers of nodules infected with $\Delta e c f S$, $\Delta e c f S / p L A F R 3$, and $\Delta e c f S /$ pecfS. These samples were fixed, thin sectioned (approximately $100 \mathrm{~nm}$ thick), stained, viewed with a JEOL 100CX electron microscope operating at $100 \mathrm{kV}$, and photographed, as previously described (Benson et al. 2005; Roth and Stacey 1989). Chlorophyll extractions were performed as previously described (Benson et al. 2005) using $0.1 \mathrm{~g}$ of fresh leaf tissue per plant. Absorbance readings of isolated chlorophyll at 664 and $647 \mathrm{~nm}$ were taken and used to calculate total chlorophyll content per gram of leaf tissue as determined by Grann and Ort (1984). To confirm the genotypes of nodulating strains, B. japonicum cells were isolated from surface-sterilized, picked nodules and were verified as wild-type USDA110 or complemented mutant strains via colony PCR and antibiotic resistance.

\section{cDNA preparation and \\ microarray hybridization and analysis.}

In-planta-derived cells were not used for the microarray due to technical challenges (i.e., the inability to harvest $\Delta e c f S$ cells from inoculated plants). Rather, we elected to perform the microarray analysis on laboratory-grown cells based on previous work showing wild-type expression of ecfStmrS under standard culture conditions (Fig. 1B) as well as observed altered growth kinetics of the ecfS mutant in culture (i.e., extended lag phase compared with wild-type or complemented strains) (data not shown). Each $B$. japonicum strain included in the study was grown in triplicate in PSY broth to an optical density of 0.5 to 0.6 at $600 \mathrm{~nm}$. Cells were harvested via centrifugation and flash frozen with liquid nitrogen, and RNA was subsequently extracted via a hot phenol method described previously (Babst et al. 1996). RNA was analyzed for integrity and lack of genomic DNA contamination. Approximately 10 to 20 $\mu \mathrm{g}$ of RNA (derived from independent cultures) was spiked with control transcripts and converted to cDNA, fragmented, and end labeled as previously described (Hauser et al. 2007; Pessi et al. 2007).

Approximately $2.3 \mu \mathrm{g}$ of each sample of fragmented and labeled cDNA was hybridized to a custom-made Affymetrix GeneChip containing 8,266 genes and 5,261 intergenic regions of the B. japonicum USDA110 genome (provided and previously described by H. Hennecke and H.-M. Fisher's group) (Hauser et al. 2007; Pessi et al. 2007) and processed accordingly. Triplicate chips of each strain (USDA110, $\Delta$ ecfS/ pLAFR3, $\Delta e c f S /$ pecfS, and $t m r S$ OE) were performed.

GeneChip hybridization signals were normalized and transformed using a scaling factor (range of scaling factor values of 1.336 to 2.717 ) and analyzed using the GeneChip Operating System software provided by Affymetrix following standardized processing steps described by Pessi and associates (2007). Briefly, genes were filtered for those that were present or marginal, categories defined by a hybridization signal above background levels in at least two out of three replicates. Those genes that fell below this threshold of expression were removed from further analyses. Analysis of variance statistical analysis was performed on the remaining data points with a false discovery rate of 0.01 and filtered for $\geq$ twofold change in expression compared with the wild type. The resulting gene lists were then annotated based on the established Kaneko and associates (2002b) nomenclature and gene calls (Kaneko et al. 2002b). Further promoter analysis was performed using motif searches (MEME Suite) (Bailey et al. 2009) and the virtual footprint algorithm (Softberry BPROM analysis tool) (Munch et al. 2005); however, a conserved motif was not identified within the promoters of the genes listed in Table 1.

\section{ACKNOWLEDGMENTS}

We thank the Functional Genomics Center Zürich as well as H.-M. Fisher and H. Hennecke (ETH, Zurich, Switzerland) for providing the custom-made B. japonicum Affymetrix GeneChips and kindly offering their expertise, assistance, and hospitality; L. Howard for her expertise and assistance in the preparation and viewing of plant tissue by electron microscopy; and R. Taylor and G. O'Toole for their critical reading of this manuscript. This work was supported by a United States Department of Agriculture grant to M. L. Guerinot. S. B. Stockwell was supported by a training grant from the National Institute of General Medical Sciences (T32GM008704) and a Graduate Assistance Area of National Need fellowship.

\section{LITERATURE CITED}

Babst, M., Hennecke, H., and Fischer, H. M. 1996. Two different mechanisms are involved in the heat-shock regulation of chaperonin gene expression in Bradyrhizobium japonicum. Mol. Microbiol. 19:827-839.

Bailey, T. L., Boden, M., Buske, F. A., Frith, M., Grant, C. E., Clementi, L., Ren, J., Li, W. W., and Noble, W. S. 2009. MEME SUITE: Tools for motif discovery and searching. Nucleic Acids Res. 37:W202-208.

Bastiat, B., Sauviac, L., and Bruand, C. 2010. Dual control of Sinorhizobium meliloti RpoE2 sigma factor activity by two PhyR-type two-component response regulators. J. Bacteriol. 192:2255-2265.

Benson, H. P., Boncompagni, E., and Guerinot, M. L. 2005. An iron uptake operon required for proper nodule development in the Bradyrhizobium japonicum-soybean symbiosis. Mol. Plant-Microbe Interact. 18:950-959.

Bolivar, F., Rodriguez, R. L., Greene, P. J., Betlach, M. C., Heyneker, H. L., Boyer, H. W., Crosa, J. H., and Falkow, S. 1977. Construction and characterization of new cloning vehicles. II. A multipurpose cloning system. Gene 2:95-113.

Braun, V., Mahren, S., and Sauter, A. 2006. Gene regulation by transmembrane signaling. Biometals 19:103-113.

Brooks, B. E., and Buchanan, S. K. 2008. Signaling mechanisms for activation of extracytoplasmic function (ECF) sigma factors. Biochim. Biophys. Acta 1778:1930-1945.

Chang, W. S., Franck, W. L., Cytryn, E., Jeong, S., Joshi, T., Emerich, D. W., Sadowsky, M. J., Xu, D., and Stacey, G. 2007. An oligonucleotide microarray resource for transcriptional profiling of Bradyrhizobium japonicum. Mol. Plant-Microbe Interact. 20:1298-1307.

Cytryn, E. J., Sangurdekar, D. P., Streeter, J. G., Franck, W. L., Chang, W. S., Stacey, G., Emerich, D. W., Joshi, T., Xu, D., and Sadowsky, M. J. 2007. Transcriptional and physiological responses of Bradyrhizobium japonicum to desiccation-induced stress. J. Bacteriol. 189:67516762.

Figurski, D. H., and Helinski, D. R. 1979. Replication of an origin-containing derivative of plasmid RK2 dependent on a plasmid function provided in trans. Proc. Natl. Acad. Sci. U.S.A. 76:1648-1652.

Flechard, M., Fontenelle, C., Trautwetter, A., Ermel, G., and Blanco, C. 2009. Sinorhizobium meliloti RpoE2 is necessary for $\mathrm{H}(2) \mathrm{O}(2)$ stress resistance during the stationary growth phase. FEMS (Fed. Eur. Microbiol. Soc.) Microbiol. Lett. 290:25-31.

Flechard, M., Fontenelle, C., Blanco, C., Goude, R., Ermel, G., and Trautwetter, A. 2010. RpoE2 of Sinorhizobium meliloti is necessary for trehalose synthesis and growth in hyperosmotic media. Microbiology 156:1708-1718.

Gourion, B., Sulser, S., Frunzke, J., Francez-Charlot, A., Stiefel, P., Pessi, G., Vorholt, J. A., and Fischer, H. M. 2009. The PhyR-sigma(EcfG) signalling cascade is involved in stress response and symbiotic efficiency in Bradyrhizobium japonicum. Mol. Microbiol. 73:291-305.

Grann, T., and Ort, D. R. 1984. Quantitation of the rapid electron donors to $\mathrm{P} 700$, the functional plastoquinone pool, and the ratio of the photosystems in spinach chloroplasts. J. Biol. Chem. 259:14003-14010.

Gruber, T. M., and Gross, C. A. 2003. Multiple sigma subunits and the 
partitioning of bacterial transcription space. Annu. Rev. Microbiol. 57:441-466.

Guerinot, M. L., and Chelm, B. .K 1986. Bacterial aminolevulinic acid synthase activity is not essential for leghemoglobin formation in the soybean/Bradyrhizobium japonicum symbiosis. Proc. Natl. Acad. Sci. U.S.A. 83:1837-1841.

Hauser, F., Lindemann, A., Vuilleumier, S., Patrignani, A., Schlapbach, R., Fischer, H. M., and Hennecke, H. 2006. Design and validation of a partial-genome microarray for transcriptional profiling of the Bradyrhizobium japonicum symbiotic gene region. Mol. Genet. Genomics 275:55-67.

Hauser, F., Pessi, G., Friberg, M., Weber, C., Rusca, N., Lindemann, A., Fischer, H. M., and Hennecke, H. 2007. Dissection of the Bradyrhizobium japonicum NifA+sigma54 regulon, and identification of a ferredoxin gene $(\mathrm{fdxN})$ for symbiotic nitrogen fixation. Mol. Genet. Genomics 278:255-271.

Humann, J. L., Ziemkiewicz, H. T., Yurgel, S. N., and Kahn, M. L. 2009. Regulatory and DNA repair genes contribute to the desiccation resistance of Sinorhizobium meliloti Rm1021. Appl. Environ. Microbiol. 75:446453.

Kaneko, T., Nakamura, Y., Sato, S., Minamisawa, K., Uchiumi, T., Sasamoto, S., Watanabe, A., Idesawa, K., Iriguchi, M., Kawashima, K., Kohara, M., Matsumoto, M., Shimpo, S., Tsuruoka, H., Wada, T., Yamada, M., and Tabata, S. 2002a. Complete genomic sequence of nitrogen-fixing symbiotic bacterium Bradyrhizobium japonicum USDA110. DNA Res. 9:189-197.

Kaneko, T., Nakamura, Y., Sato, S., Minamisawa, K., Uchiumi, T., Sasamoto, S., Watanabe, A., Idesawa, K., Iriguchi, M., Kawashima, K., Kohara, M., Matsumoto, M., Shimpo, S., Tsuruoka, H., Wada, T., Yamada, M., and Tabata, S. 2002b. Complete genomic sequence of nitrogen-fixing symbiotic bacterium Bradyrhizobium japonicum USDA110 (Supplement). DNA Res. 9:225-256.

Kazmierczak, M. J., Wiedmann, M., and Boor, K. J. 2005. Alternative sigma factors and their roles in bacterial virulence. Microbiol. Mol. Biol. Rev. 69:527-543.

Kovach, M. E., Elzer, P. H., Hill, D. S., Robertson, G. T., Farris, M. A., Roop, R. M., 2nd, and Peterson, K. M. 1995. Four new derivatives of the broad-host-range cloning vector pBBR1MCS, carrying different antibiotic-resistance cassettes. Gene 166:175-176.

Lang, K., Lindemann, A., Hauser, F., and Gottfert, M. 2008. The genistein stimulon of Bradyrhizobium japonicum. Mol. Genet. Genomics 279:203-211.

Libault, M., Govindarajulu, M., Burg, R. H., Tsuey Ong, Y., Puricelli, K., Taylor, C. G., Xu, D., and Stacey, G. 2011. A dual-targeted soybean protein is involved in Bradyrhizobium japonicum infection of soybean root hair and cortical cells. Mol. Plant-Microbe Interact. 24:1051-1060.

Lindemann, A., Moser, A., Pessi, G., Hauser, F., Friberg, M., Hennecke, H., and Fischer, H. M. 2007. New target genes controlled by the Bra- dyrhizobium japonicum two-component regulatory system RegSR. J. Bacteriol. 189:8928-8943.

Llamas, M. A., van der Sar, A., Chu, B. C., Sparrius, M., Vogel, H. J., and Bitter, W. 2009. A novel extracytoplasmic function (ECF) sigma factor regulates virulence in Pseudomonas aeruginosa. PLoS Pathog. 5:e1000572.

Munch, R., Hiller, K., Grote, A., Scheer, M., Klein, J., Schobert, M., and Jahn, D. 2005. Virtual Footprint and PRODORIC: An integrative framework for regulon prediction in prokaryotes. Bioinformatics 21:4187-4189.

Pessi, G., Ahrens, C. H., Rehrauer, H., Lindemann, A., Hauser, F., Fischer, H. M., and Hennecke, H. 2007. Genome-wide transcript analysis of Bradyrhizobium japonicum bacteroids in soybean root nodules. Mol. Plant-Microbe Interact. 20:1353-1363.

Roth, L. E., and Stacey, G. 1989. Bacterium release into host cells of nitrogen-fixing soybean nodules: The symbiosome membrane comes from three sources. Eur. J. Cell Biol. 49:13-23.

Rowley, G., Spector, M., Kormanec, J., and Roberts, M. 2006. Pushing the envelope: Extracytoplasmic stress responses in bacterial pathogens. Nat. Rev. Microbiol. 4:383-394.

Sauviac, L., Philippe, H., Phok, K., and Bruand, C. 2007. An extracytoplasmic function sigma factor acts as a general stress response regulator in Sinorhizobium meliloti. J. Bacteriol. 189:4204-4216.

Schweizer, H. D. 1993. Small broad-host-range gentamycin resistance gene cassettes for site-specific insertion and deletion mutagenesis. Biotechniques 15:831-834.

Small, S. K., Puri, S., Sangwan, I., and O'Brian, M. R. 2009. Positive control of ferric siderophore receptor gene expression by the Irr protein in Bradyrhizobium japonicum. J. Bacteriol. 191:1361-1368.

Staron, A., Sofia, H. J., Dietrich, S., Ulrich, L. E., Liesegang, H., and Mascher, T. 2009. The third pillar of bacterial signal transduction: Classification of the extracytoplasmic function (ECF) sigma factor protein family. Mol. Microbiol. 74:557-581.

Staskawicz, B., Dahlbeck, D., Keen, N., and Napoli, C. 1987. Molecular characterization of cloned avirulence genes from race $\mathrm{O}$ and race 1 of Pseudomonas syringae pv. glycinea. J. Bacteriol. 169:5789-5794.

Watson, N. 1988. A new revision of the sequence of plasmid pBR322. Gene 70:399-403.

Yang, J., Sangwan, I., Lindemann, A., Hauser, F., Hennecke, H., Fischer H. M., and O'Brian, M. R. 2006. Bradyrhizobium japonicum senses iron through the status of haem to regulate iron homeostasis and metabolism. Mol. Microbiol. 60:427-437.

\section{AUTHOR-RECOMMENDED INTERNET RESOURCES}

The MEME Suite motif-based sequence analysis tool: meme.nbcr.net Softberry BPROM online promoter prediction tool:

linux 1.softberry.com/berry.phtml?topic=bprom\&group=help\&subgroup $=$ gfind $\mathrm{b}$ 